\title{
A GENERIC TAXONOMY OF SHOPPING MOTIVES AMONG HYPERMARKETS (HYPER-STORES) CUSTOMERS AND THE RELATIONSHIP WITH DEMOGRAPHIC VARIABLES
}

\author{
M Dhurup, Vaal University of Technology, South Africa
}

\begin{abstract}
Purpose of the study: Noting that the motive for shopping is located within the paradigm of buying behaviour of consumers; the study seeks to complement existing literature by examining whether a configuration of shopper motives could be developed, thereby revealing taxonomy of hypermarket (hyper-store) shoppers. In addition the study seeks to establish whether shopping motives is shaped by demographic variables.
\end{abstract}

Problem statement: Although the motive for shopping and its antecedents has been approached from various perspectives, it has been accentuated in literature that traditional utilitarian aspects of product acquisition explanations may not fully reflect the totality of a shopping experience. With such affirmations, shopping may be harmonised with hedonic activities when considered within a hypermarket/hyper-store South African context.

Methodology: The study adopted a conceptual framework for identifying relatable factors (using exploratory factor analysis) that influence consumer motivation for shopping within hypermarket (hyper-store) environments. Reliability and validity of the scale was established.

Findings: A 13 item scale was developed. Shopping seems to be both a utilitarian and a hedonic consumption experience with three auxiliary categories of hedonic motivations, namely diversion, recreational and sensory stimulated shoppers. In examining the motives for shopping and demographic variables, diversion appears to vary with levels of education.

Value of the research: Enhancing one's understanding of the "softer" issues of shopping, namely diversion, recreational and sensory stimulated shoppers is essential, as they represent possible differentiating factors in a highly competitive and often commoditised retail market. Acquaintance of distinct shopper segments is useful for retailers in assembling marketing communication strategies and designing appealing store environments.

Conclusion: Whilst shopper typologies may hold several advantages in theory and practice for both the consumers and retailers; the study has made an unpretentious and encouraging start in the understanding of hypermarket/hyper-store shopper patronage.

Key words and phrases: Shopping motives, utilitarian motive, hedonic motive, hypermarkets (hyper-stores).

\section{INTRODUCTION AND A THEORETICAL PERSPECTIVE}

As new retail formats continue to develop and secure their positions in the market, knowledge of what attributes attract customers to stores has become important (Paulins \& Geisfield, 2003:371). To remain competitive, store based retailers must be prepared to implement changes in their retail mix. Within the South African retail industry supermarkets, hypermarkets (hyper stores) are renowned for their high level of competitive rivalry especially within the various national chains stores (Evalgeldis, 1994:5). In the last twenty years hypermarkets have made great inroads in the retailing field (Farquhar, 2002:6 and Farhangmehr, Marques \& Silva, 2000:197).

Such progression is evident in the retail sector, where major retail stores (including supermarkets and hypermarkets) were responsible for more than half of South Africa's turnover on groceries, toiletries and confectionery (GTC) (Neilson, 2000:16). Yet this contributed only 2 per cent of the stores selling these products. This constitutes 54.4 per cent (R35.2 billion) of the total national sales on GTC. Driven by highly competitive management, larger national chains are continuously fighting for market share and apply pressure on smaller, independent retailers. Such pressure takes the form of everyday low pricing (EDLP), cheaper private label and generic brands (with double you money back guarantee), loyalty programmes, and national advertising campaigns (Dhurup, Venter \& Oosthuyzen, 
2005:140). With retailers in active engagement to maintain, gain or increase their share of the market using various approaches, consumers are in the process given greater choices among the various types of retail outlets (Peter, Leszczyc \& Timmermans, 2001:494). At one end of the retail spectrum, there is a plethora of small-scale retail operations offering convenient location and high quality products. At the other end, lie the mega-stores, hypermarkets (hyper-stores) and shopping malls offering one stop convenience and lower prices. With a variety of store configurations including those of shopping malls and shopping centres, shoppers may be influenced to shop for reasons other than product acquisition.

Early research demonstrates that consumer shopping orientations is not only influenced by product acquisition. Current shopping experience involve more than consumer acquisition of goods (Fiore \& Kim, 2007:421). Ever since Stone (1954:36-45) and Tauber (1972:46) suggested numerous shopping motives or orientations for retail store visits, researchers (Cox, Cox \& Anderson, 2005:251) and scholars alike have agreed that there are emotional aspects of shopping motives, besides function or product acquisition. Jin \& Kim, (2003:397) view shopping motives as 'drivers' of behaviour that brings consumers to the marketplace. In addition, consumers' evaluation of a store's attribute and shopping outcomes, such as shopping satisfaction vary according to the shopping motives (Groeppel-Klein, Thelen \& Antretter, 1999:63). To make informed decisions, retailers need to know more about their motives for shopping and consumer store choice decisions.

The study inter alia provides insights into shopping motives within various shopping contexts in order to develop a generic typology for hypermarket (hyperstore) shoppers. Consequently, this study examines essential variables that influence functional and non-functional motives for shopping. Previous studies in the study of the relationship between shopping motives and demographic variables are reviewed.

\section{PROBLEM ORIENTATION}

Shopper motives are rooted in shoppers' strong state of basic needs. In addition, consumers may therefore have different needs across different cultures. Hence, shopping motives may be shaped by the culture in which people live (Jin \& Kim, 2003:396). From a retailer's perspective, understanding local customers' perception towards diverse retail formats is crucial as such perceptions may be susceptible to cultural differences. From an international perspective Mc Cort (1993:91) reviewed literature from cross cultural fields of psychology, anthropology, consumer behaviour and international marketing in an attempt to show that culture has an influence on consumer behaviour constructs of perception, information processing and self-concept. Ackennam and Tellis (2001:57) resonates similar views that national characteristics of shopping behaviour are unique and shaped within the constraints and features of national boundaries. Whilst this may be true in international retailing, such affirmations may also be appropriate when considered in a South African context. The South African market is characterised by heterogeneous groups of consumers. Such heterogeneity exists in the food and non-food markets, which comprise customers with different cultures, income, tastes, expectations, and motives. These unique characteristics in turn provide traces to shared norms, values and learnt buying behaviour patterns.

Research evidence also suggests that shopping behaviour can also be learned from school, parents and from societal norms that define what is desirable (Cialdini, Raymond \& Carl, 1990:1019). In summary, shopping behaviour, like any other behaviour is susceptible to influences and shaped by norms of the social group with which one identifies. With the multiplicity of influences inherent amongst consumers in their motives to shop, the study builds on the following research question:

- What are the motives for shopping in hypermarkets/ hyper-stores?

- Are shopping motives shaped by demographic variables?

In light of the research questions, an overview of shopping motives study is pursued in the section which follows. 


\section{SHOPPING MOTIVES}

Numerous studies have been conducted after the early works of Tauber (1972:46-59) on why do people shop (Lindquist, 1974-1975:29-38; Monroe \& Guiltnan, 1975:19-28; Hansen \& Deutscher,1977-1978:59-95; Williams, Pianter \& Nicholas, 1978:27-42; Mattson, 1982:46-58; Keng \& Ehrenberg, 1984:399-409; Westbrook \& Black, 1985:78-103; Dawson; Bloch \& Ridgeway, 1990:408427; Babin, Darden \& Griffin, 1994:644-657 and Moschis, Curasi \& Bellenger, 2004:123-133). Concomitant with the views associated with the above authors, perhaps Westbrook and Black (1985:78) sagaciously define motives as "forces instigating behaviour to satisfy intense need states". Thus identifying shopping motives may provide an important foundation to comprehend consumer needs and motives which in turn can be used to segment markets. A brief review of various studies is undertaken in appraising shopper types.

Stone (1954:36) distinguish four shopper types: The economic consumer who has a careful approach to shopping with specific reference to merchandise. The personalised shopper attempts to seek personalised relationships with store personnel. The ethical shoppers are those shoppers who are willing to sacrifice lower prices and wider selection of goods. The apathetic shoppers are those shoppers who shop out of necessity, with the shopping activity holding no intrinsic interest. They construe shopping as a burden.

Later, the study by Tauber (1972:47) examined six personal motives, role playing, diversion, self gratification, learning new trends, physical activity and sensory stimulation and five social motives, social experience, communication, peer group attraction, status and pleasure of bargaining for shopping. The author arrived at the conclusion that securing a purchase was not the only motive for shopping. In fact many of the motives had little to do with purchases. One of the shopping motives was, diversion, i.e. getting away from the routine of everyday life with diversion as a form of relaxation, which could be extended into self-gratification by spending money on oneself. Thus for such a shopper, the buying process has a certain internal stimuli, separate from the actual purchase. Shopping therefore becomes a social experience outside the home. In contrast, Stephenson \& Willett (1969:316-322) proposed a taxonomy based on actual patronage and shopping behaviour. They classified shopper typologies into four categories: A store loyal shopper, a compulsive and recreational shopper, a convenience shopper and a price-bargaining and conscious shopper.

Within the grocery shopping context, Darden and Ashton (1974:99-112) factor analysed consumers' rating of preferences and arrived at seven configurations: quality oriented, fastidious shopper, convenience, demanding, trading stamp collectors, stamp avoiders and apathetic shoppers. The study by Moschis (1976:61-70) identified six shopper types: store loyal shoppers, brand loyal shoppers, "specials" shopper, psycho-socialising shopper, name conscious shopper and a problemsolving shopper. Shopping motives, according to Westbrook and Black (1985:87) was classified into seven dimensions namely, anticipated utility, role enactment, negotiation, choice optimisation, affiliation, power and authority, and stimulation whereas Dawson, Bloch and Ridgeway (1990:415) identified two broad motives, product and experiential motives. Baben et al. (1994:650) classified motives into utilitarian versus hedonic shopping motives. The hedonic experience may raise the level of consumer involvement and arousal in a shopping experience (Nicholis, Li, Mandokovic, Roslow \& Kranendonk, 2000:107). Such hedonic experiences can occur when consumers engage in enjoyment and fun during a shopping trip. Hedonic shopping motives are based on the quality of the shopping experience, rather than towards information gathering or product acquisition (Boedeker, 1995:19). Donavan Rossiter, Marcoolyn and Nesdale, (1994:284) on the other hand found that the longer individuals stay in a retail environment the more they are likely to spend. In contrast, the authors found that utilitarian shoppers are well focused; regard shopping as a serious experience and as a means to serve their functional needs.

In addition, shopping motives may also seem to relate to the time and money spent during the shopping trip. Dawson et al. (1990:421) for example, found that shopping motives influence the duration of time spent in the store as well as the desire to explore the shopping environment. Leszczyc, Peter, Sinha and Timmermans, (2000:324) on the other hand identified that store choice is dependent on the timing of the shopping trip as consumers may go to a smaller local store for short "fill in" trips and go to a larger store for regular shopping trips. Excitement is also seen as one of the key emotions that have been considered to attract customers into a shopping mall (Wakefield \& 
Baker, 1998:518). Excitement is defined as a positive emotional state that consists of high levels of pleasure and arousal (Russell, 1980:1163) and relates to retail outcomes such as satisfaction (Dawson et al., 1990:410), repatronage intentions and a desire to stay in a mall (Wakefield \& Baker, 1998:518). Ackennam and Tellis (2001:60) also concurs that shopping as an activity is not just about product acquisition but is also very much part of social relationships. Shopping does not have to be just for the functional purpose of product acquisition. Sherry (1990:27) examined the role of shopping in a flea market and resonate similar views. The author suggests that people are just not lead to a flea market for the utilitarian function of the purchase, but also for satisfaction they derive from the shopping environment. Research has also found that recreational shoppers who are likely to have a relatively high level involvement with shopping, visit the retail environment more frequently than those who shop for utilitarian reasons (Roy, 1994:142) and derive intrinsic enjoyment from the process of shopping (Cox et al., 2005:253).

Within the scope of shopping motives, researchers have also associated shopping motives with store patronage. Jin and Kim (2003:396) established that shopping motives better explained future store patronage intentions than extrinsic motives. In a book by Dawson et al. (1990:422), only product motives had a significant relationship with patronage. These findings suggest that consumers often revisit the store where their shopping motives are most satisfied. Research undertaken by Farhangmehr et al. (2000:197) found that hypermarkets are preferred choice for customers who frequently purchased packaged goods, due to its low prices and convenient one-stop shopping.

From the above review it seems that great variation across studies is evident on how, or what basis, the various shopper types are discerned. Moreover, the focus of the studies has ranged from specific product types to group of products, to the retail marketplace in general (Westbrook \& Black, 1985:78). Evident from these taxonomies is that there is a diverse array of shopper types. The non-functional and functional values are usually described in utilitarian terms. The utilitarian perspective is based on the assumption that consumers are rational problem-solvers (Rintamäki, Kanto, Kuusela \& Spence, 2006:6). Hence the utilitarian perception stresses functional, product-centric thinking. Within a South African context, Terblanche (1999:141) conducted an exploratory study on the perceived benefits derived from visits to a super regional shopping centres found that there functional, recreational and social dimensions motives for such visits. The non-functional side of shopping emphasises the experiential part of shopping emphasising the social, emotional and epistemic values.

Only a few studies on shopping motives were consistent across a spectrum of retail environments. This diversity may be due to the different empirical approaches and retail contexts that were used. In summary, most of the prior research on shopping motives has assumed that the primary motives underlying the reasons for shopping are functional including overall convenience and information seeking (Rohm \& Swaminathan, 2004:749).

Given the array of motives for shopping, the review was extended in order to elucidate an understanding on whether any relationship exists between shopping motives and demographic variables.

\section{SHOPPING MOTIVES AND DEMOGRAPHIC VARIABLES}

Store choice research emphasises the use of individual variables such as demographics, socioeconomic or psychological as primary predictors of store selection (Mattson, 1982:46). If demographic factors reflect consumers shopping motives, retailers can easily segment markets and respond to consumer motives with a range of retail factors (Jin \& Kim, 2003:396). However the finding of earlier studies on this relationship is varied. For example, Westbrook and Black $(1985: 100)$ found that the six shopping motives did not differ significantly in demographic variables such as age, marital status, occupation, income levels and education. Groeppel-Klein et al. (1999:69) also established that there were no significant differences in demographic characteristics and the three shopper clusters. Recently, Moshis et al. (2004:125) found that age and gender had little to do with the motives for shopping. Williams et al. (1978:35) however found shopping motives vary with age and marital status whereas Jin and Kim (2003:404) found that shopping motives are not simply a function of consumers' socio-economic standing. Contrary to these findings Cox et al. (2005:255) established that several shopping pleasures vary with the age of the customer. For example, browsers tend to be younger and apply novelty-seeking behaviours. These authors also found that lower-income consumers are less 
likely to use price-saving tactics than their middle class counterparts. Berman and Evans (2004:207) also resonates the view that middle income consumers tend to be conscientious shoppers, compared to low-income consumers. In South Africa, there is no empirical evidence to the researcher's knowledge on hypermarket/hyper-store shopping motives, suggesting a relationship between hypermarket shoppers and demographic variables.

\section{PURPOSE OF THE STUDY}

In quintessence, the study seeks to complement existing literature by examining whether a configuration of shopper motives could be developed, thereby revealing taxonomy of hypermarket (hyper-store) shoppers. In addition the study seeks to establish whether shopping motives is shaped by demographic variables.

\section{RESEARCH DESIGN AND METHODOLOGY}

In conceptualising the purpose of the study, the following framework in the research design was followed. The design details the procedures followed in eliciting the required information with reference to the compilation of the sample, questionnaire construction and data collection in order to determine possible answers to the research questions.

\section{Sample Composition}

Both male and female consumers where chosen as respondents. Hypermarket (hyper-stores) was chosen as our object of study. Firstly, the situational variable (geographical distance) was suited for determining shopping motives and its relation with demographic variables. Secondly, a wide variety of the different segments of the population groups frequent these stores. These stores guarantee variation in terms of competitiveness, products, brand variety, assortment and service orientation. Pen-ultimately these stores are perspicaciously accentuated and located with essential tenants which, offer reciprocal support to these stores. Finally, open spaces for ease of shopping and opened parking also suited the purpose of the study.

\section{Questionnaire Development}

The questionnaire developed was based on multi-item scales of prior research studies (Tauber, 1972:47; Lindquist, 1974-1975: 29-38; Westbrook \& Black, 1985:78-103; Lumpkin, Greenberg \& Goldstucker, 1985:75-104; Dawson et al., 1990:408-427; Farhangmehr et al. 2000:197-206; Kim \& Jin, 2001:236-255; Jin and Kim, 2003:396-419 and Dong, 2003:42-71). A total of sixteen items were used to measure shopping motives. The responses were recorded on a Likert scale. The questionnaire was pre-tested using a convenience sample of twenty hypermarket (hyper store) shoppers. The respondents were administered a structured questionnaire.

\section{Data Collection}

The data was collected after the consumers completed their shopping. The rationale for such a data collection strategy was based on the theory that respondents will be aufait to the task of completing the questionnaire and will provide significant responses when they have completed their shopping (Dabholkar, Thorpe \& Rentz, 1996:9). In addition the author was assiduous to randomise the data collection procedure by conducting interviews to reduce possible shopping pattern bias, by interviewing respondents at different times of the day (morning, midday and afternoon) and at different days of the week. Such randomisation is consistent with South African research literature on store shopping experiences (Terblanche \& Boschoff, 2004:4 and Terblanche, 1999:142). Furthermore, representivity was achieved by ensuring that respondents visited the stores at least once a month. Shoppers were interviewed after they had completed the majority of their shopping for the day so that valid measures of the time spent "shopping" could be elicited (Reynolds, Ganesh \& Luckett, 2002:687). In addition, it was felt that the exit interview would capture recency effects and real visitation experiences (Sinha \& Banerjee, 2004:485). Post graduate marketing research students who were trained in field work were used as fieldworkers. 
A sample of 250 was deemed to be adequate to develop and refine the instrument (Finn \& Louviere, 1996:244; Frost \& Kumar, 2000:368 and Rajagopalan \& Heitmeyer, 2005:91). A total of 273 questionnaires were completed with 22 questionnaires being rejected, due to errors or incomplete responses; 251 questionnaires were used for analysis. This was an adequate sample size for the use of multivariate statistical techniques such as factor analysis (Hair, Anderson, Tatham \& Black, 1995:103) to analyse the data.

An integral part of a research design process requires an analysis and interpretation of the results.

The sections which follow provide a detail explanation in this regard.

\section{ANALYSIS AND INTERPRETATION OF FINDINGS}

Data analysis comprised four distinct phases namely, an assessment of the underlying dimensions of the instrument by using exploratory factor analysis, an assessment of reliability (by computing Cronbach alpha), validity of the instrument and an analysis of variance (ANOVA). An exposé of the exploratory factor analysis and the subsequent extraction of factors are discussed below.

\section{Exploratory Factor Analysis}

The appropriateness of factorability was initially established by conducting both the Bartlett's Tests of Sphericity and the Kaiser-Meyer-Olkin test (KMO), a measure of sampling adequacy (MSA). The approximated chi square value of the Bartlett's Test of Sphericity was 977.425 (df =91) at an observed significance level of 0.000 rejecting the hypothesis that the population correlation matrix is an identity matrix, i.e. with zero correlations. The Kaiser-Meyer-Olkin measure of sampling adequacy was 0.80 which is considered "meritorius" by Kaiser (1974:35).

To give effect to the purpose of the research and in establishing the internal structures on the motives for shopping, an exploratory factor analysis was performed in order to examine the dimensionality of the scale. The principal components analysis with varimax rotation was performed for data reduction purpose (Reynolds, Ganesh \& Luckett, 2002:689; Smith \& Carsky, 1996:76 and Kim \& Jin, 2001:244). Varimax rotation was also used in order to minimize the number of variables with high loading on a factor, thereby enhancing the interepretability of factors (Malhotra \& Birks, 2003:582). Variable loading of 0.50 and above were retained (Churchill \& lacobucci, 2002:809). Item reduction and scale purification was then undertaken whereby items with low factor loadings, communalities and low-itemto-total correlations were investigated (Aldlaigan \& Buttle, 2002:369). The iterative process was re-run several times until a clear factor structure emerged. The determination of the number of factors to be extracted were theoretically accomplished by applying a combination of statistical techniques namely, percentage of variance explained, the eigenvalue criterion, the scree plot and taking into account the interpretability of factors. Four factors with thirteen variables were extracted. The final factors structure and eigenvalues is reported in Table 1 . The eigenvalues in respect of the four dimensions ranged from 4.30 to 1.00 . Together, these factors accounted for approximately $60 \%$ of the variance which according to Malhotra (2004:567) is satisfactory.

Table 1: Exploratory factor loading results

\begin{tabular}{|l|l|l|l|l|}
\hline & Factor 1 & Factor 2 & Factor 3 & Factor 4 \\
\cline { 2 - 5 } & Diversion & Recreational & $\begin{array}{l}\text { Sensory } \\
\text { stimulated }\end{array}$ & Functional \\
\hline Forget day to day activities & 0.772 & & & \\
\hline To be refreshed & 0.635 & & & \\
\hline Spend time with friends & 0.552 & & & \\
\hline Escape from routine life & 0.802 & & & \\
\hline To have a good time & & 0.667 & & \\
\hline To be energised & & 0.699 & & \\
\hline $\begin{array}{l}\text { To visit a place that conveys a level of } \\
\text { achievement }\end{array}$ & & 0.737 & & \\
\hline To create a new image for myself & & 0.530 & & \\
\hline I enjoy crowds & & & 0.771 & \\
\hline
\end{tabular}




\begin{tabular}{|l|l|l|l|l|}
\hline Watch other people shopping & & & 0.789 & \\
\hline Find product assortment that I need & & & & 0.729 \\
\hline $\begin{array}{l}\text { Take look at products considered for } \\
\text { purchase }\end{array}$ & & & & 0.764 \\
\hline Take advantage of specials on promotion & & & & 0.759 \\
\hline Eigenvalue & 4.30 & 1.84 & 1.21 & 1.00 \\
\hline \% of variance explained & 30.76 & 13.20 & 8.76 & 7.20 \\
\hline Cumulative \% & 30.76 & 43.96 & 52.64 & 59.84 \\
\hline
\end{tabular}

Each of the motivations for shopping is briefly discussed in the light of theoretical explanations of human motivation and prior research findings. Factor one labelled diversion shoppers, comprised four variables and accounted for $30.76 \%$ of the variance. The diversion shopper dimension relate, interalia shopping in order to forget day-to-day activities, to be refreshed, spend time with friends and escape with routine life. Such shoppers escape crowds as encountered in shopping malls and enjoy shopping primarily as a kinaesthetic experience (Cox et al., 2005:252) with fun (Kim \& Jin, 2001:244). This group is similar to Arnold and Reynold's (2003:79) "gratification shoppers" which involves shopping for stress relief, shopping to alleviate a negative mood, and shopping as a special treat to oneself. Babin et al. (1994: 651) also recognised the value of shopping as a self-gratifying, escapist, and therapeutic activity, describing respondents views who perceive shopping as a "pick me up" and a "lift" when one feel depressed. Finally, shopping has been acknowledged in the literature as a form of emotion-focused coping in response to stressful events to get one's mind off a problem (Mathur \& Moschis, 1999:233). Such shopper's motives inter-alia may include eliciting product ideas and meeting with friends, which further demonstrates consumers' external reliance as a source of information (Kaur \& Singh, 2007:133).

Factor two, labelled a recreational shopper comprised four variables and accounted for $13.20 \%$ of the variance. A recreational shopper shops in order to have a good time, be energised and visit places that convey a level of achievement which creates a new image for oneself. They enjoy shopping as a leisure activity in order to source information on merchandise quality fashion and trends and consequently "browse a store's merchandise without an intention to buy" (Bellenger \& Korgaonkar, 1980:78). This dimension is analogous to the dimension identified by Westbrook and Black, (1985:87) and Terblanche (1990:144) which support the notion that recreational shoppers are a significant force in the retail market as they come and go and do spend money. The recreational aspects of shopping is further grounded in the collection of affiliation theories of human motivation (Arnold \& Reynolds, 2003:79) which collectively focus on people being altruistic, cohesive, and seeking acceptance and affection in interpersonal relationships. A significant amount of prior research has uncovered the social aspects of shopping motivation. Stone $(1954 ; 36)$ first identified a "personalising" shopper; as one who seeks personal relationships while shopping, whereas Moschis (1976: 66) acknowledged these shoppers as "psycho-socialising" shoppers.

Factor three, labelled a sensory stimulated shopper comprised two variables accounted for $8.67 \%$ of the variance. These shoppers are stimulated by enjoying crowds and watch other people shopping. The dimension resembles those found in previous shopping typology studies such as those of Tauber (1972:47), Bloch, Ridgway and Dawson, (1994:32). Westbrook and Black (1985:79) posit that there are "dependent shoppers" that require social support while shopping. Dholakia (1999: 156) concurs that for such consumers, shopping is a "spectacle in which one is both a performer and spectator ... seeing it and being seen". These studies also are in congruence with the current study inferring that sensory stimulated shoppers try to satisfy their social needs which offers them with an array of opportunities to socialise. Wakefield and Baker (1998:529) resonates similar views that shoppers derive pleasure from sensory aspects of the retail environment especially in store design and atmospherics, whilst others derive pleasure by experiencing a change in physical environments. A sensory stimulated shopper is also similar to prior findings which confirm that shoppers often seek sensory stimulation while shopping. For example, Arnold and Reynolds (2003:79) uncovered the personal shopping motive of sensory stimulation whilst Babin et al. (1994:651) refer to adventurous aspects of shopping as a factor that may produce hedonic shopping value. 
Factor four, labelled a functional shopper comprised three variables accounted for $7.20 \%$ of the variance. In literature these shoppers are synonymous to the utilitarian (economic) shoppers (Roy, 1994:147; Dholakia, 1999:156 and Kim \& Jin, 2001:245). Such shoppers take shopping as a serious activity in order to find a broad assortment of merchandise and take advantages of special offers. These shoppers are price-bargaining, conscious shoppers and shop in order to obtain value (Reynolds et al., 2002:692). In addition such bargain oriented shoppers have been portrayed as cool and calculating shoppers in contrast to pleasure-driven recreational shoppers (Cox et al., 2005:251). Some studies identified functional (economic or utilitarian, product-acquisition) as a characteristic of not only shoppers (Stone, 1954:41; Stephenson \& Willett, 1969:316) but also of their orientation towards shopping (Roy, 1994:142). These shoppers are less likely to enjoy shopping as a leisure activity (Bellenger \& Korgaonkar, 1980:78). Old as time in literature Stone (1954: 38) described the price-oriented functional shopper as "... approximation to the economic man of the classical economist ...caring only about quick efficient sale of merchandise ....and ... able to participate in the market in a detached, interested and alert manner". In contrast, some researchers have suggested that the pursuance for low prices is not driven solely by "cool cognition" but may also be a source of emotional satisfaction that create a sense of accomplishment (Cox et al., 2005: 251). These authors further reiterates that paying low price provokes feelings of pride, intelligence and a sense of achievement and that bargain-hunting shopper's gain pleasure from "beating the system". Hence monetary savings reduce the pain of paying and contribute to utilitarian value (Rintämaki, Kanto, Kuusela \& Spence, 2006:12).

In summary, shopping seems to be both a utilitarian and hedonic consumption experience (Arnold \& Reynolds, 2003:79) with three auxiliary categories of hedonic motivations (diversional, recreational and sensory stimulated shoppers). In congruence with implications from consumer behaviour research it seems that shopping may be pleasurable in that certain groups of shoppers are more interested in delightful outcomes than others (Millan \& Howard, 2007:475). The utilitarian aspects of shopper of shoppers are characterised by being task-related and rational, while the hedonic shoppers have a propensity to be inclined to facets of behaviour that relate to the multi-sensory, fantasy and emotional aspects of consumption. Hedonic shopping motives are similar to the task orientation of utilitarian shopping motives, only the "task" is affiliated with hedonic fulfilment, such as experiencing fun, amusement, fantasy, multi-sensory and emotional aspects of one's experience (Hirschman \& Holbrook,1982:92).

The study proceeds to examine the reliability and validity of the research instrument.

\section{Reliability and Validity}

The remaining 13 items were then subjected to an internal consistency reliability analysis with the computation of coefficient alpha (Cronbach $\alpha$ ). Item reduction and scale purification was undertaken whereby items with low factor loadings, communalities and low-item-to-total correlations were investigated (Chandon, Leo \& Philippe, 1997:68 and Aldlaigan \& Buttle, 2002:369). The iterative process was re-run several times until deleting an individual item from the instrument could not further improve the Cronbach alpha coefficients.

These results are reported in table 2. The reliability for factors one, two, three, were considered adequate i.e. above 0.70 (Nunnally, 1978:230) whereas factor four indicates marginal internal consistency. These values of internal consistency are deemed acceptable as Kim and Jin (2001:244) and Roy (1994:147) also reported similar values in their shopping orientation studies. In addition, the coefficient alpha values of the total scale $(\alpha=0.823)$ supported the inclusion of the fourth dimension.

Table 2: Reliability analysis: Cronbach alpha coefficients

\begin{tabular}{|l|l|}
\hline Dimensions & Cronbach $\alpha$ \\
\hline Diversion & 0.758 \\
\hline Recreational & 0.727 \\
\hline Sensory stimulated & 0.701 \\
\hline Functional & 0.647 \\
\hline Total scale & 0.823 \\
\hline
\end{tabular}


Whilst reliability is a necessary but not sufficient indicator of the psychometric soundness of an instrument, the validity of the scale was also assessed. To ensure that the scale satisfies content validity the questionnaire was pre-tested with a sample of twenty hypermarket shoppers on a one-toone basis. With de-briefing changes were made to the questionnaire with regard to wording, phrasing and sequence. The instrument was further purified during the various stages in the iterative process.

In addition to reliability, the validity of the scale was assessed through discriminant, construct and convergent validities. Discriminant validity in this context refers to the ability of the research instrument to assess the uni-dimensionality of underlying dimensions. Furthermore, evidence of reliability and validity confirm the construct validity of the measuring instrument (Bosch, Boschoff, \& Louw, 2003:43). In assessing discriminant and construct validity of the research instrument, exploratory factor analysis was conducted. In each step of this procedure, scale purification was undertaken where individual items were removed from the research instrument to improve the discriminant and construct validity until all items demonstrated acceptable levels of discriminant validity (i.e. all the items load on a common factor only with no cross-loadings) and construct validity (i.e. all the items relating to each dimension have factor loadings of at least 0.50 ). Furthermore, the reliability of a scale as measured by the coefficient alpha reflects the degree of cohesiveness among scale items and is also an indirect indicator of convergent validity (Parasuraman, Zeithaml \& Berry, 1991:439).

In order to establish specific differences between and within groups in the demographic variables multiple comparison post-hoc tests was employed to establish where the differences existed. For the sake of simplicity only where significant differences were established between the shopper motive dimensions and demographic variables; explanations are substantiated with tables reflecting the analysis of variance and post-hoc results.

\section{Analysis of Variance (ANOVA)}

The results of the exploratory factor analysis were subsequently used to create summated scales that were used as dependent variables and demographic data was used as independent variables. The sample comprised $41 \%$ males and $49 \%$ females with majority $(47.4 \%)$ being married respondents. The greater majority of the respondents (64.6\%) were in the age categories of 26 to 45 years. Just more than half $(50.2 \%)$ of the respondents earned a salary of R40 000 to R120 000 with $7.6 \%$ earning an annual income above R200 000. Finally, the samples were fairly well educated, with $14.3 \%$ of the shoppers having completed some technical and almost $40 \%$ completed university education. Overall, the data revealed ample variance in response for all items.

The four motives for shopping were then examined for differences in means across the following demographic factors: gender, age, marital status, education and income at a 0.05 level of significance. The results are interesting in that no significant differences are shown in the statistics apart from diversion and the level of education. These results are not surprising as variation in results has been reported in previous research studies (Westbrook \& Black,1985:100; Groeppel-Klein et al., 1999:69; Moshis et al., 2004:125; Williams et al., 1978:35 and Jin \& Kim, 2003:404).

\section{Gender}

The Levene's test for equality of variance was used for the analysis where gender was an independent and the four shopping motives were the dependent variable. No significant differences were noted between male and female respondents and their motives for shopping. Moschis et al. (2004:126) also found that all shopping motives are of equal importance to both male and female consumers.

\section{Marital status}

For the purpose of analysis marital status was reduced to two categories, namely married and single (single, divorced, widowed and separated). No significant differences were noted between marital status and their motivations for shopping. Previous research undertaken by Groeppel-Klein et al. (1999:69) also found that shopper motives did not significantly differ in terms of marital status. 


\section{Level of education}

Education levels were grouped into the following categories: No formal education, high school or below, technical college, University of Technology and University. No statistical significant differences were noted for the different levels of education and the diversion (factor 1) sensory stimulated (factor 3 ) and functional shoppers (factor 4). However differences were identified through the use of ANOVA between recreational (factor 2) $(F=2.564, p=0.039)$ and the following categories: no formal education and University of Technology, no formal education and University, high school and University of Technology and high school and University. These results are reflected in table 3.

Table 3: Analysis of variance (ANOVA): Shopping motive dimensions and level of education

\begin{tabular}{|c|c|c|c|c|c|c|}
\hline FACTOR & TEST & $\begin{array}{l}\text { Sum of } \\
\text { squares }\end{array}$ & df & $\begin{array}{l}\text { Mean } \\
\text { square }\end{array}$ & $\bar{F}$ & Sig \\
\hline \multirow[t]{3}{*}{ Diversion } & Between groups & 1.753 & 4 & 0.438 & 0.601 & 0.662 \\
\hline & Within groups & 179.371 & 246 & 0.729 & & \\
\hline & Total & 181.124 & 250 & & & \\
\hline \multirow[t]{3}{*}{ Recreational } & Between groups & 7.122 & 4 & 1.781 & $2.564^{*}$ & 0.039 \\
\hline & Within groups & 170.808 & 246 & 0.694 & & \\
\hline & Total & 177.930 & 250 & & & \\
\hline \multirow{3}{*}{$\begin{array}{l}\text { Sensory } \\
\text { stimulated }\end{array}$} & Between groups & 6.167 & 4 & 1.542 & 1.867 & 0.117 \\
\hline & Within groups & 203.112 & 246 & 0.826 & & \\
\hline & Total & 209.279 & 250 & & & \\
\hline \multirow[t]{3}{*}{ Functional } & Between groups & 0.250 & 4 & 0.062 & 0.153 & 0.962 \\
\hline & Within groups & 100.604 & 246 & 0.409 & & \\
\hline & Total & 100.853 & 250 & & & \\
\hline
\end{tabular}

Post-hoc analysis was conducted to ascertain at what level of education, specific differences occurred. These results are illustrated in table 4. Respondents with no formal education and those with high school education and below vary with reference to their diversion motive for their shopping compared to their University of Technology and University counterparts. Kim and Jim (2001:249) also reported similar findings of group differences in jobs and level of education. Westbrook and Black (1995:100) on the contrary found that shopper types grouped by shopping motives did not significantly differ in terms of level of education whilst Cox et al. (2005:252) argues that variation in the need for diversion reflects fundamental differences in social class attitude towards shopping.

Table 4: Post-hoc multiple comparison- diversion and level of education

\begin{tabular}{|c|c|c|c|c|c|c|c|c|}
\hline \multirow[t]{2}{*}{$\begin{array}{l}\text { Dependent } \\
\text { variable }\end{array}$} & \multirow[t]{2}{*}{$\begin{array}{l}\text { Type } \\
\text { of test }\end{array}$} & \multirow[t]{2}{*}{$\begin{array}{l}\text { Education } \\
\text { category(I) }\end{array}$} & \multirow[t]{2}{*}{$\begin{array}{l}\text { Education } \\
\text { category(J) }\end{array}$} & \multirow[t]{2}{*}{$\begin{array}{c}\text { Mean } \\
\text { diff (I-J) }\end{array}$} & \multirow[t]{2}{*}{$\begin{array}{l}\text { Std } \\
\text { error }\end{array}$} & \multirow[t]{2}{*}{ Sig } & \multicolumn{2}{|c|}{$\begin{array}{l}95 \% \\
\text { confidence } \\
\text { interval }\end{array}$} \\
\hline & & & & & & & $\begin{array}{l}\text { Lower } \\
\text { bound }\end{array}$ & $\begin{array}{l}\text { Upper } \\
\text { bound }\end{array}$ \\
\hline \multirow[t]{6}{*}{ Diversion } & \multirow[t]{4}{*}{ Dunnett } & \multirow[t]{4}{*}{$\begin{array}{l}\text { No formal } \\
\text { education }\end{array}$} & High school & -0.31696 & 0.32654 & 0.333 & $\overline{-}-9601$ & 0.3262 \\
\hline & & & Technical & -.051042 & 0.32570 & 0.118 & $\begin{array}{l} \\
1.1519\end{array}$ & 0.1311 \\
\hline & & & UoT & $-\overline{0.71759 *}$ & 0.31054 & 0.022 & 1.3293 & $-\overline{0.1059}$ \\
\hline & & & University & $-\overline{0.64875^{*}}$ & 0.30616 & 0.035 & $\begin{array}{l} \\
1.2518\end{array}$ & -0.457 \\
\hline & \multirow[t]{2}{*}{ Scheffe } & \multirow[t]{2}{*}{$\begin{array}{l}\text { High } \\
\text { school }\end{array}$} & $\begin{array}{l}\text { No formal } \\
\text { ed }\end{array}$ & 0.31696 & 0.32654 & 0.333 & $\begin{array}{l}- \\
\end{array}$ & 0.9601 \\
\hline & & & Technical & -0.19345 & 0.19780 & 0.329 & $\overline{-}-5831$ & 0.1961 \\
\hline
\end{tabular}




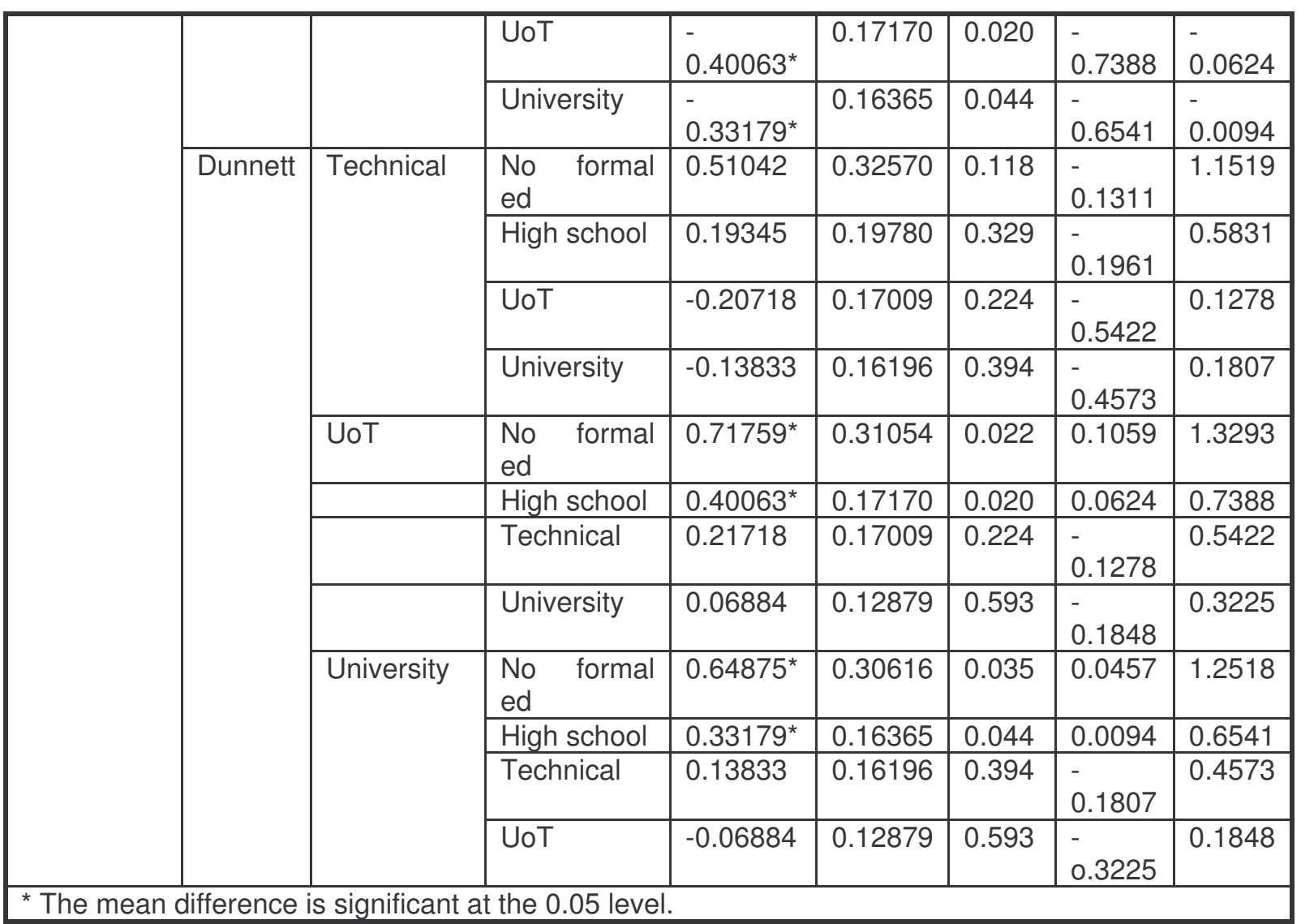

Level of income

The income level of respondents were measured through a categorical variable with grouping of below R40 000, R40 001-R80 000, R80 001-R120 000, R120001-R160 000, R160 001-R200 000 and over R200 000. No significant differences were noted between the motives for shopping and the respective level of income. These findings support the findings of earlier studies (Westbrook \& Black; 1985:100 and Groeppel-Klein et al. 1999:69), that shopping motives are not necessarily influenced by income. For example, browsing which entails the "examination of a store's merchandise for recreational or informational purposes" does not involve an outlay of money, may be source of shopper enjoyment and a recreational motive for shopping (Cox et al., 2005:252).

Age

Age was measured using the following categorical variables: 18-25 years, $26-35$ years, 36-45 years, 4655 years, 56-65 years and over 65 years. No statistical differences were noted between age and the four motives for shopping. Mochis (2004:126) arrived at a similar conclusion that shopping motives vary very little with age. However, Cox et al. (2005:255) on the contrary found that the elderly consumers (age > 65) are especially likely to derive satisfaction from certain aspects of shopping. They are more likely to enjoy being pampered by salespeople than any other group, are more likely to enjoy shopping for exercise. However, such variation may be due to the context, these studies were done. For example, Moschis et al. (2004:125); Williams et al. (1978:35); Westbrook and Black, $(1985: 100)$ and Dholakia, (1999:157) conducted their studies in a variety of shopping situations and arrived at different conclusions. In addition, these studies showed variation in the number and typology of dimensions for the varied contexts.

\section{RECOMMENDATONS}

A number of recommendations for retailers are apparent. Acquaintance of distinct shopper segments is useful for retailers in assembling marketing communication strategies and designing appealing 
store environments. Recreational shoppers are very important to the retail trade. For example, communication material may require astute adaptation to attract shoppers who are motivated for different hedonic reasons; as they are a significant proportion of the shopping public. This could be accomplished by focussing on the experiential aspects of the store environment, positing the total shopping experience as an adventure or a place to de-stress.

The functional or economic shopper may be attracted by a convenient location, but the recreational shopper wants more. To attract the latter group of consumers, retailers may have to offer attractive décor and an exciting shopping experience. Retailers should attempt to make creative use of atmospherics in order to attract recreational shoppers. Bellenger and Korgaonkar (1980:80) submit that recreational shoppers are more likely to go on shopping trips without a pre-planned purchase in mind. Apart from shopper segmentation, retailers could use the scale to investigate the direction and strength of hedonic motives among their current customers.

The general profile of a recreational shopper suggests greater amounts of impulse purchases. The fact that recreational shoppers use shopping for information seeking further accentuates the need for effective in-store promotions. In general, marketers can take motivational factors into consideration when designing promotional and other communication programmes targeted to hypermarket/hyperstore shoppers. Managements of hyperstores/hypermarkets can on the other hand increase shoppers' buying intentions or visitation by providing more recreational or diversion activities by ameliorating their retailing and marketing strategies. In-store displays or promotions may become important, given the tendency to make purchases based on impulse (Zhuang, Tsang, Zhou, Li \& Nicholls, 2006:40). Since shoppers are stimulated by enjoying crowds, watch other people shopping or buying (Kaur \& Singh 2007:136) for the reason than one has been there (whether noticed or not) may provide cues for managements of hypermarkets/hyperstores to create avenues for impulse purchases.

\section{IMPLICATIONS FOR FUTURE RESEARCH}

Out-shopping, an avenue for further research can be pursued in the future as the study did not consider the effects of sales leakages from one trade are to another. Shopping by people from rural in urban towns and cities may provide pertinent sources for the motives for shopping, perhaps; consumers' ethnocentric propensity to out shopping. Retailers therefore need to better understand how rural or out of town consumers spend money and what factors influence their decisions to spend money in or out of major retail areas within their regions.

With the paucity of research on shopper orientations which focused on the multicultural nature of the South African population recorded in literature (Visser \& du Preez, 2001:8) researchers also need to establish whether there are any culture-specific shopping motives. These shopping motives may provide an important avenue and serve as a foundation to understand local consumers' needs in order to segment markets.

Future research can examine the association between shopping motivations and outcomes such as satisfaction, store loyalty and retention. Scholars and researchers alike also need to be cautious in the application of the scale to other shopping contexts as evidence in generalizability is obliged. Further research relating to these motivations and its relationship with demographic variables is warranted. The information disclosed in this study may assist practitioners to better understand South African shoppers' behaviour in hypermarkets/hyper-stores and, as a consequence, to undertake more challenging marketing strategies to reduce uncertainty when exploiting retail locations.

Prevailing retail systems are also evolving towards an increasing dichotomy where smaller speciality stores try to co-exist with increasingly larger stores. With such patterns of co-existence it becomes necessary to establish avenues for future research; whether co-existing and smaller speciality stores benefit in aiding to attract the recreational, diversion or sensory stimulated shoppers. If positive reciprocal relationships can be established, then hypermarkets/hyper-stores can nurture such relationships and attract appropriate stores to their advantage. 


\section{CONCLUSION}

Whilst shopper typologies may hold several advantages in theory and practice for both the consumers and retailers (Visser \& du Preez, 2001:1); the study has made an unpretentious and encouraging start in understanding of hypermarket/hyper-store shopper patronage. While the motives are cited in previous studies in varied international retail environments; it does provide contemporary views among consumers within a South African hypermarket/hyper-store setting which may enhance our understanding on the motives for shopping in a specific type of a retail milieu. With the exception of the diversion dimension of shopping motivation and level of education, shopping motives do not seem to vary with consumer demographics. The profile that emerges from the data is consistent with the findings of previous research (Bellenger \& Korgaonkar, 1980:91).

A growing need exist for managements' of hypermarkets/hyper-stores to augment their formats to create a total retail experience to assert their influence within a diverse South Africa retail environment. Further research within a broader competitive retail environment is warranted. For example, can hypermarkets/hyperstores co-exist with regional shopping malls? Can hypermarkets/hyperstores co-exist with strip centres and regional shopping malls? Consequently in delineating retail environments, perceptions from shoppers become relevant.

\section{REFERENCES}

Ackennam D \& Tellis G. 2001. Can culture affect prices? A cross-cultural study of shopping and retail prices. Journal of Retailing, 77(1):57-82, Spring.

Aldlaigan AH \& Buttle FA. 2002 SYSTRA-SQ: a new measure of bank service quality. Industrial Journal of Service Industry Management, 13(3):362-381.

Arnold MJ \& Reynolds KE. 2003. Hedonic Shopping motives. Journal of Retailing, 79:77-95.

Babin BJ, Darden WR \& Griffin M. 1994. Work and /or fun: measuring hedonic and utilitarian shopper value. Journal of Consumer Research, 20(4):644-657.

Berman B \& Evans J. 1998. Retail Management: A Strategic Approach. Englewood Cliffs (NJ): Prentice-Hall.

Bellenger DN \& Korgaonkar PK. 1980. Profiling the Recreational Shopper. Journal of Retailing, 56(3):77-92.

Bloch PH, Ridgway, NM \& Dawson SA. 1994. The shopping mall as a consumer habitat. Journal of Retailing, 79(1):23-42.

Boedeker M. 1995. New-type and traditional shoppers. A comparison of two major consumer groups. International Journal of Retail \& Distribution Management, March 17-27.

Bosch JK, Boschoff C \& Louw L. 2003. Empirical perspectives on the motivational and learning strategies of undergraduate students in Business management: An exploratory study. Management Dynamics, 12(4):39-50.

Cialdini RB, Raymond R \& Carl AK. 1990. A focus theory of normative conduct: recycling the concept of norms to reduce littering in public places. Journal of Personality and Social Psychology, 58(June):1015-1026.

Chandon L, Leo L \& Philippe J. 1997. Services Encounter Dimensions-A dyadic perspective: Measuring the dimensions of service encounters as perceived by customers and personnel. International Journal of Service and Industry Management, 8(1):65-86.

Churchill GA (Jr) \& lacobucci D. 2002. Marketing Research: Methodological Foundations. 8th ed. FortWorth: Harcourt College Publishers. 
Cox AD, Cox D \& Anderson RD. 2005. Reassessing the pleasures of store shopping. Journal of Business Research, 58:250-259.

Dabholkar A, Thorpe, ID \& Rentz OJ. 1996. A measure of retail service quality: scale development and validation. Journal of the Academy of Marketing Science, 24(1):3-16.

Darden WR \& Ashton D. 1974. Psycholographic profiles of patronage preference groups. Journal of Retailing, 50:99-112, Winter.

Dawson S, Bloch PH \& Ridgway NM. 1990. Shopping motives, emotional states, and retail outcomes. Journal of Retailing, 66(4):408-427.

Dholkakia RR. 1999. Going shopping: key determinants of shopping behaviours and motivations. International Journal of Retail \& Distribution Management, 27(4):154-165.

Dhurup M, Venter PF \& Oosthuyzen A. 2005. A factor analytical service quality measurement scale for supermarkets in South Africa. South African Journal of Economic and Management Science, 8(2): 140-153.

Donavan R, Rossitter JR, Marccolyn G \& Nesdale A. 1994. Store atmosphere and purchasing behaviour. Journal of Retailing, 70(3):283-294.

Dong MK. 2003. Inter-relationships among store image, store satisfaction, and store loyalty among Korea discount retail patrons. Asia Pacific Journal of Marketing and Logistics, 15(4):42-71.

Evangeldis A. 1994. Customer perceptions of service quality at grocery supermarkets outlets. University of Witswatersrand. (Dissertation:MBA)

Farquhar J. 2002. A brief look at the history of SA Retailing. Progressive Trends, 6:6-7.

Farhangmehr M, Marques S \& Silva J. 2000. Consumer and retailer perceptions of hypermarkets and traditional retail stores in Portugal. Journal of Retailing and Consumer Services, 7:197-206.

Finn A \& Louviere JJ. 1996. Shopping Centre image, Consideration, and Choice: Anchor Store Contribution. Journal of Business Research, 35:241-251.

Fiore AM \& Kim J. 2007. An integrative framework capturing experiential and utilitarian shopping experience. International Journal of Retail \& Distribution Management, 35(6):421-442.

Frost FA \& Kumar M. 2000. INTSERVQUAL-an internal adaptation of the GAP model in a Large Service Organisation. Journal of Service Marketing, 14(5):358-377.

Groeppel-Klein A, Thelen E \& Antretter C. 1999. The impact of shopping motives on store assessment. European Advances in Consumer Research, 4:63-72.

Hair JF(Jr), Anderson RE, Tatham RL \& Black WC. 1995. Multivatiate Data Analysis: with readings. Englewoods Cliffs, New Jersey: Prentice-Hall.

Hansen RA \& Deutscher T. 1977/1978. An empirical investigation of attribute importance in retail store selection. Journal of Retailing, 53(4):59-95, Winter.

Hirschman EC \& Holbrook MB. 1982. Hedonic consumption: emerging concepts, methods and propositions. Journal of Marketing, 40(3):92-101.

Kaiser HF. 1974. An index of factorial simplicity. Psychometrike, 29(1):31-36

Kaur P \& Singh R. 2007. Uncovering retail shopping motives of Indian youth. Young Consumers, 8(1):128-138. 
Keng KA \& Ehrenberg ASC. 1984. Patterns of store choices. Journal of Marketing Research, 21:399-409.

Kim JO \& Jin B. 2001. Korean customers patronage of discount stores: domestic vs multinational discount store shoppers' profiles. Journal of Consumer Marketing, 18(3):236-255.

Jin B \& Kim J O. 2003. A typology of Korean discount shoppers: shopping motives, store attributes, and shopping outcomes. International Journal of Service Industry Management, 14(4):396-419.

Lindquist JD. 1974/1975. Meaning of image. Journal of Retailing, 50(4):29-38, Winter.

Leszczyc P, Peter TL, Sinha A \& Timmermans HJP. 2000. Customer store choice dynamics: An analysis of the competitive market structure for grocery stores. Journal of Retailing, 76(3):323-346.

Lumpkin JR, Greenberg BA \& Goldstucker JL. 1985. Marketplace needs of elderly: Determinant attributes and store choice. Journal of Retailing, 61(2):75-104, Summer.

Malhotra NK. 2004. Marketing research; an applied orientation. $4^{\text {th }}$ Ed. New Jersey: Prentice-Hall.

Malhotra NK \& Birks DF. 2003. Marketing research: an applied orientation. $2^{\text {th }}$ Ed. London:

Prentice-Hall.

Mathur A \& Moschis GP. 1999. Stress and consumer behaviour: coping strategies of older adults. Journal of Marketing Practice: Applied Marketing Science, 5(6/7/8):233-247.

Mattson BE. 1982. Situational influences on store choice. Journal of Retailing, 58(3):46-58, Fall.

Mc Cort DT. 1993. Culture and Consumer behaviour: toward an understanding of cross-cultural consumer behaviour in international marketing. Journal of International Consumer Marketing, $6(2): 91-127$.

Millan ES \& Howard E. 2007. Shopping for pleasure? Shopping experiences of Hungarian consumers. International Journal of Retail and Distribution Management, 35(6):474-487.

Monroe KB \& Guiltnan JP. 1975. A path analytic exploration of retail patronage influences. Journal of Consumer Marketing, 2:19-28.

Moschis G. 1976. Shopping orientations and consumer uses of information. Journal of Retailing, 52:61-71.

Moschis G, Curasi C \& Bellinger D. 2004. Patronage motives of mature consumers in the selection of food and grocery stores. Journal of Consumer Marketing, 21(2):123-133.

Neilson AC. 2000. Taking stock of retailing" AC Neilson's store census, Progressive Trends, 6:16-17.

Nicholis JAF, Li F, Mandokovic T, Roslow S \& Kranendonk CJ. 2000. Journal of Consumer Marketing, 17(2):106-119.

Nunnally JC. 1978. Psychometric theory. $2^{\text {nd }}$ ed. New York. McGraw-Hill.

Parasuraman A, Zeithaml, VA \& Berry LL. 1991. Refinement and reassessment of the SERVQUAL scale. Journal of Retailing, 67(4):420-450.

Paulins VA \& Geisfield LV. 2003. The effect of consumer perceptions of store choice attributes on apparel store preferences. Journal of Fashion Marketing and Management, 7(4):371-385.

Peter TL, Leszczye P \& Timmermans H. 2001. Experimental choice analysis of shopping strategies. Journal of Retailing, 77:493-509. 
Rajagopalan R \& Heitmeyer J. 2005. Ethnicity and consumer choice: A study of consumer levels of involvement in Indian ethnic apparel and contemporary American clothing. Journal of Fashion Marketing and Management, 9(1):83-105.

Reynolds KE, Ganesh J \& Luckett M. 2002. Traditional malls vs factory outlets; comparing shopper typologies and implications for retail strategy. Journal of Business Research, 55:687-696.

Rintamäki T, Kanto A, Kuusela H \& Spense MT. 2006. Decomposing the value of department store shopping into utilitarian, hedonic and social dimensions: Evidence from Finland. International Journal of Retail \& Distribution Management, 34(1):6-24.

Rohm AJ \& Swaminathan V. 2004. A typology of online shoppers on shopping motivations. Journal of Business Research, 57(1):748-757.

Roy A. 1994. Correlates of mall frequency. Journal of Retailing, 70(2):139-161.

Russell JA. 1980. A circumplex model of affect. Journal of Personality and Social Psychology, 39:1161-1178.

Sinha PK \& Banerjee A. 2004. Store choice behaviour in an evolving market. Industrial Journal of Retail \& Distribution Management, 32(10):482-494.

Sherry JF(Jr). 1990. A socio-cultural analysis of a Midwestern Flea Market. Journal of Consumer Research, 17(June):13-30.

Smith MF \& Carsky ML. 1996. Grocery shopping behaviour: a comparison of involved and uninvolved consumers. Journal of Retailing and Consumer Services, 3(2):73-80.

Stephenson RP \& Willet RP. 1969. Analysis of consumers' retail patronage strategies:. In Mc Donald, P.R. (Eds). Marketing involvement in Society and the economy, Chicago

Stone PG. 1954. City shoppers and urban identification: observation on the social psychology of city life. American Journal of Sociology, 60:36-45, July.

Tauber E. 1972. Why do people shop? Journal of Marketing, 36:46-59, October

Terblanche NS. 1999. The perceived benefits derived from visits to a super regional shopping centre: an exploratory study. South African Journal of Business Management, 30(40):141-146.

Terblanche NS \& Boschoff C. 2004. The In-store shopping experience: A comparative study of supermarkets and clothing store customers. South African Journal of Business Management, 35(4): $1-10$.

Visser EM \& Du Preez R. 2001. Apparel shopping orientatioms: Two decades of research. Journal of Family Ecology and Consumer Sciences, 29:1-10

Wakefield KL \& Baker J. 1998. Excitement in a mall: Determinants and effects on shopping response. Journal of Retailing, 74(4):515-539.

Westbrook RA \& Black WC. 1985. A motivation-based shopper typology. Journal of Retailing, 61(1): 78-103.

Williams RH, Pianter JJ \& Nicholas HR. 1978. A policy-oriented typology of grocery shoppers. Journal of Retailing, 54(1):27-42.

Zhung G, Tsang ASL, Zhou N, Li F \& Nicholls JAF. 2006. Impacts of situational factors on buying decisions in shopping malls: An empirical study with multinational data. European Journal of Marketing, 40(1/2):17-42. 